\title{
Hepatitis C bei Drogenpatienten: Therapie ist wirksam, erfolgreich und notwendig
}

Der 1. Oktober wurde zum internationalen Hepatitis-C-Tag erklärt. In der Schweiz ist die Schweizerische Expertengruppe für virale Hepatitis (SEVHep) bestrebt, auf diese virale Infektionskrankheit aufmerksam zu machen. Hepatitis $C$ ist auch hierzulande weiter verbreitet, als vielfach angenommen wird. Vor allem bei drogenabhängigen Patientinnen und Patienten tritt sie sehr häufig auf.

Philip Bruggmann

Korrespondenz:

Dr. med. Philip Bruggmann Leiter Somatik ARUD Zürich Poliklinik Zokl 1

Sihlhallenstrasse 30

CH-8026 Zürich

p.bruggmann@arud-zh.ch

www.arud-zh.ch
Herr L. hat es geschafft: sechs Monate lang kam er täglich in die Drogenpoliklinik und bezog nebst dem Methadon seine Ribavirindosis, freitags verabreichte er sich vor Ort zusätzlich die Spritze mit pegyliertem Interferon. Anfänglichen Motivationsproblemen, verursacht durch Nebenwirkungen, konnten mit häufigen Kurzterminen erfolgreich begegnet werden. Heute, ein halbes Jahr später, konnten wir ihm die erfreuliche Nachricht überbringen, dass noch immer keine Hepatitis-C-Virus-RNA in seinem Blut zu finden ist und er somit als geheilt gilt.

Die Methadonbehandlung mit ihren häufigen Patientenkontakten bietet eine ideale Voraussetzung für eine erfolgreiche Hepatitis-CTherapie [1]. Die jährliche Neuinfektionsrate ist heute bei Drogenabhängigen am höchsten [2]. Mehr als die Hälfte aller Hepatitis-C-Patienten haben sich über Drogenkonsum infiziert. Sie werden in Zukunft die grösste Gruppe von Leberzirrhosepatienten und somit von Transplantationskandidaten ausmachen [3].

Bis vor kurzem galten in den nationalen und internationalen Therapierichtlinien Drogenabhängige als nicht behandelbar [4]. Es konnte nun aber in mehreren Studien belegt werden, dass sowohl die Prognose vor Therapie als auch die Durchführbarkeit und der Erfolg einer Behandlung bei Drogenabhängigen gleich günstig sind wie bei Personen, die sich nicht über Drogenkonsum infiziert haben $[5,6]$.

Das Hepatitis-C-Virus wird parenteral übertragen. Bis Anfang der neunziger Jahre - vor Beginn von systematischem Screening - waren die Hauptinfektionswege Bluttransfusionen und Blutprodukte. Für eine Hepatitis-C-Virus-Übertragung reichen kleinste Mengen Blut. So erfolgt die Ansteckung bei Drogenkonsum über gemeinsames Verwenden von Drogenzubereitungs- und Applikationsmaterial (nicht nur Nadel und Spritze, sondern auch Löffel, Filter, Inhalationsröhrchen usw.).

Unzureichende Hygiene beim Piercen oder Tätowieren sind weitere Risikofaktoren.

Kleinste Blutreste können sich aber auch auf Rasierklingen, Manicurebesteck und Zahnbürsten befinden, was bei Haushaltkontakten mit Hepatitis-C-Infizierten beachtet werden sollte. Selten sind vertikale (Mutter-Kind) und sexuelle Ansteckungen, wobei bei risikoreichen Sexualpraktiken mit Blutbeteiligung gehäufte Infektionen beschrieben sind $[7,8]$.

Insgesamt sind in der Schweiz schätzungsweise bis zu 70000 Menschen mit dem HepatitisC-Virus infiziert, das entspricht 1\% der Gesamtbevölkerung. Aufgrund des häufig jahrzehntelang symptomlosen Verlaufes weiss etwa die Hälfte nichts von ihrer Ansteckung. Das Hepatitis-C-Virus ist die häufigste Ursache für eine chronische Leberentzündung. Während bei einem Teil der Betroffenen keine ernsthaften Folgeschäden auftreten, schreitet die Krankheit bei etwa $20 \%$ fort und führt zu Leberzirrhose und Leberkrebs.

Goldstandard der Hepatitis-C-Therapie ist eine Kombination von pegyliertem Interferon und Ribavirin. Je nach Genotyp dauert die Behandlung 6 bis 12 Monate. Die Erfolgsrate liegt bei $50-85 \%$.

Die SEVHep organisiert in verschiedenen Schweizer Städten Anlässe zum Internationalen Hepatitis-C-Tag: www.sevhep.ch 


\section{Literatur}

1 Mauss S, Berger F, Goelz J, Jacob B, Schmutz G. A prospective controlled study of interferon-based therapy of chronic hepatitis $\mathrm{C}$ in patients on methadone maintenance. Hepatology. 2004; 40:120-4.

2 Alter MJ. Epidemiology of hepatitis C. Hepatology. 1997;26:62S-65S

3 Edlin BR. Prevention and treatment of hepatitis C in injection drug users. Hepatology. 2002; 36(suppl 1):210-9.

4 Reimer J, Schulte B, Castells X, Schäfer I, Polywka S, Hedrich D, et al. Guidelines for the Treatment of Hepatitis C Virus Infection in Injection Drug Users: Status Quo in the European Union Countries. CID. 2005;40(suppl 5):373-8.
5 Robaeys G., Buntinx F. Treatment of hepatitis C viral infections in substance abusers. Acta Gastroenterol Belg. 2005;68:55-67.

6 Backmund M, Meyer K. Hepatitis-C-Therapie während der Substitutionsbehandlung. Suchtmed. 2006;8(2):115-8.

7 Murphy E, Bryzman S, Glynn S, Ameti D, Thomson R, Williams A, et al. Risk factors for hepatitis $\mathrm{C}$ virus infection in United States blood donors. NHLBI Retrovirus Epidemiology Donor Study (REDS). Hepatology. 2000;31(3):756-62.

8 Gambotti L. Acute hepatitis C infection in HIVpositive men who have sex with men in Paris, France, 2001-2004. Eurosurveillance. 2005; 10:115-7. www.eurosurveillance.org. 